
\title{
Research Suate \\ Echinicola Salinicaeni sp. nov., A Novel Bacterium Isolated from Saltern
}

\author{
Han Zhao
}

Shandong University

Chun-Yi Song

Shandong University

Rui Yin

Shandong University

Yan-Jun Yi

Shandong University

Shuai-Ting Yun

Shandong University

Ying-Xiu Li

Shandong University

Yanxia Zhou ( $\nabla$ zhouyx@sdu.edu.cn )

Shandong University

\section{Research Article}

Keywords: Echinicola salinicaeni sp. nov. , 16S rRNA gene sequence, Novel species, Polyphasic taxonomy

Posted Date: June 25th, 2021

DOI: https://doi.org/10.21203/rs.3.rs-474138/v1

License: (c) (1) This work is licensed under a Creative Commons Attribution 4.0 International License.

Read Full License 
1 Echinicola salinicaeni sp. nov., a novel bacterium isolated from

2 saltern

3 Han Zhao $\cdot$ Chun-Yi Song $\cdot$ Rui Yin' Yan-Jun Yi $\cdot$ Shuai-Ting Yun $\cdot$ Ying-Xiu

4

5

\section{Li · Yan-Xia Zhou*}

Marine College, Shandong University, Weihai 264209, China

*Correspondence: Yan-Xia Zhou; Email: zhouyx@sdu.edu.cn

\section{Abstract}

A Gram-stain-negative, aerobiotic, pink, motile, rod-shaped bacterium, designated $\mathrm{P} 51^{\mathrm{T}}$ was isolated from saline silt samples in Yantai, China. The novel isolate was able to grow at $4-42{ }^{\circ} \mathrm{C}$ (optimum $33{ }^{\circ} \mathrm{C}$ ), $\mathrm{pH} 4.0-9.0$ (optimum 7.0 ) and with $0-11.0 \%$ $\mathrm{NaCl}$ (optimum $4.0 \%$, w/v). It could grow at $4{ }^{\circ} \mathrm{C}$, which was different from the neighbour strains. The draft genome consisted of 4111 genes with a total length of $5139782 \mathrm{bp}$ and $39.9 \% \mathrm{G}+\mathrm{C}$ content. The 16S rRNA gene sequence analysis indicated that strain $\mathrm{P} 51^{\mathrm{T}}$ was a member of the genus Echinicola and most closely related to 'Echinicola shivajiensis' with pair-wise sequence similarity of 97.7\%. Genome analysis identified genes encoding proteins relating to carbon source utilization such as glycoside hydrolases and glycosyl transferases; carotenoid biosynthesis pathway and $\beta$-lactam resistance pathway were observed. Strain $\mathrm{P} 51^{\mathrm{T}}$ shared average nucleotide identity value below $84.7 \%$, average amino acid identity value between of $70.8-89.3 \%$, digital DNA-DNA hybridization identity of between $17.9-28.2 \%$ with the closely related type strains within the genus Echinicola. The sole menaquinone was MK-7; the major fatty acids were iso- $\mathrm{C}_{15: 0}$, summed feature $3\left(\mathrm{C}_{16: 1} \omega 7 c\right.$ and/or $\left.\mathrm{C}_{16: 1} \omega 6 c\right)$, summed 
23 feature 4 (anteiso- $\mathrm{C}_{17: 1} \mathrm{~B}$ and/or iso- $\mathrm{C}_{17: 1} \mathrm{I}$ ) and summed feature 9 (iso- $\mathrm{C}_{17: 1} \omega 9 c$ and/or

24 10-methyl $\mathrm{C}_{16: 0}$ ); the polar lipids included one phosphatidylethanolamine, one 25 unidentified aminophospholipid, one unidentified phospholipid, three unidentified 26 aminolipids and one unknown lipid. Based on phenotypic, chemotaxonomic, and 27 phylogenetic analyses, strain $\mathrm{P}^{1} 1^{\mathrm{T}}$ represents a novel species of the genus Echinicola, 28 for which the name Echinicola salinicaeni sp. nov. is proposed. The type strain is P51 $29\left(\right.$ KCTC $\left.82513^{\mathrm{T}}=\mathrm{MCCC} 1 \mathrm{~K} 04413^{\mathrm{T}}\right)$.

30 Keywords: Echinicola salinicaeni sp. nov. $\cdot 16 \mathrm{~S}$ rRNA gene sequence $\cdot$ Novel 31 species $\cdot$ Polyphasic taxonomy 


\section{Abbreviations}

MA Marine agar 2216

MB Marine broth 2216

MEGA Molecular Evolutionary Genetics Analysis

HPLC High Performance Liquid Chromatography

HEPES N-(2Hydroxyethyl)Piperazine-N'-2-Ethanesulfonic Acid

CAPSO 3-Cyclohexylamino-2-Hydroxypropanesulfonic Acid Sodium Salt

MES 2-(N-Morpholino) ethane-sulfonic acid

PIPES Piperazine-1,4-Bisethanesulfonic Acid

Tricine N-[Tris(Hhydroxymethyl)Methyl] Glycine

KCTC Korean Collection for Type Cultures

JCM Japan Collection of Microorganisms

MCCC Marine Culture Collection of China

GHs Glycoside Hydrolases

GTs Glycosyl Transferases

CBM Carbohydrate-Binding Modules

ANI Average Nucleotide Identity

AAI Average Amino Acid identity

dDDH digital DNA-DNA Hybridization

\section{Introduction}

In 2006, the genus Echinicola was first established (Nedashkovskaya et al. 2006), which belonged to the family Cyclobacteriaceae in the phylum Bacteroidetes. Presently, 
the genus Echinicola comprises seven species, which were motile by gliding, rodshaped, heterotrophic, with non-diffusible carotenoid pigments, strictly aerobic bacteria with menaquinone-7 (MK-7) as major respiratory quinone, iso- $\mathrm{C}_{15: 0}$ and summed feature $3\left(\mathrm{C}_{16: 1} \omega 7 c\right.$ and/or $\left.\mathrm{C}_{16: 1} \omega 6 c\right)$ as major cellular fatty acids and the DNA G $+\mathrm{C}$ content ranging between 43.8 and 46.9 mol\% (Jung et al. 2017; Kim et al. 2011; Lee et al. 2017; Liang et al. 2016; Nedashkovskaya et al. 2007; Nedashkovskaya et al. 2006; Srinivas et al. 2012; Xing et al. 2020). Species of the genus Echinicola were isolated from different marine habitats such as brackish water pond, coastal sediment and the sea urchin Strongylocentrotus intermedius (Lee et al. 2017; Nedashkovskaya et al. 2006; Srinivas et al. 2012). For the first time, we isolated a novel strain $\mathrm{P} 51^{\mathrm{T}}$ from saline silt, which showed high similarity to other strains of genus Echinicola. In this study, the novel strain was Echinicola salinicaeni, described by a polyphasic approach (Vandamme et al. 1996).

\section{Materials and methods}

\section{Isolation of strain $\mathrm{P}^{\mathrm{T}}{ }^{\mathrm{T}}$}

Strain $\mathrm{P} 51^{\mathrm{T}}$ was isolated from silt samples taking from Muping saltern in Yantai, Shandong Province, China $\left(121^{\circ} 40^{\prime} 20^{\prime \prime}\right.$ E, $\left.37^{\circ} 26^{\prime} 39^{\prime \prime} \mathrm{N}\right)$. The silt samples were diluted with sterile water. The dilution was then inoculated on marine agar 2216 (MA, Becton Dickinson). After incubation at $30{ }^{\circ} \mathrm{C}$ for 2 days, pink colonies were obtained and designated as strain $\mathrm{P} 51^{\mathrm{T}}$. Subcultivation was performed routinely on MA at $30^{\circ} \mathrm{C}$. The type strains, 'Echinicola shivajiensis' JCM $17847^{\mathrm{T}}$, Echinicola sediminis KCTC $52495^{\mathrm{T}}$, Echinicola pacifica $\mathrm{KCTC} 12368^{\mathrm{T}}$, Echinicola vietnamensis MCCC $1 \mathrm{~K} 04353^{\mathrm{T}}$, Echinicola 
jeungdonensis KCTC $23122^{\mathrm{T}}$ were purchased from their respective collection institutions.

All strains were cultured under comparable conditions for physiological and chemotaxonomic characterizations, unless otherwise specified. They were preserved at $-80{ }^{\circ} \mathrm{C}$ in sterile seawater supplemented with $15.0 \%(\mathrm{v} / \mathrm{v})$ glycerol.

\section{Phylogenetic analysis of 16S rRNA gene and whole genome sequencing}

The $16 \mathrm{~S}$ rRNA gene was amplified by PCR technique using universal primers, $27 \mathrm{~F}$ (5' - AGA GTT TGA TCM TGG CTC AG -3') and 1492R (5' - TAC CTT GTT ACG ACT T -3')(Kim et al. 2014). Comparison of 16S rRNA gene sequences was carried out using NCBI BLAST and the EzBioCloud (Yoon et al. 2017). Phylogenetic trees were inferred using neighbour-joining (NJ), maximum-likelihood (ML) and maximum-parsimony (MP) trees carried out in MEGA version 7.0 (Kumar et al. 2016). The robustness of the topologies for the trees was evaluated by bootstrap analysis based on 1000 resamplings.

The draft genome sequence was sequenced on the Illumina HiSeq-PE150 platform.

The sequenced reads were assembled using SOAP, Spades, and Abyss De novo software. The annotation of genome sequence was processed using the GeneMarkS, rRNAmmer, and Rfam software. These operations were all implemented by Beijing Novogene Bioinformatics Technology Co, Ltd. (Beijing, China). The genes involved in metabolic pathways were analysed in detail by using information from the Kyoto Encyclopedia of Genes and Genomes (KEGG) databases (Kanehisa et al. 2016). Protein-encoding regions were performed with the Rapid Annotation using Subsystem Technology (RAST) server (http://rast.nmpdr.org/rast.cgi) (Aziz et al. 2008) and the 
UniProtKB/Swiss-Prot (Consortium 2019). The presence of gene clusters encoding secondary metabolites was predicted by using the antiSMASH 5.0 database (Blin et al. 2019).

To further clarify the genetic relatedness between strain $\mathrm{P} 51^{\mathrm{T}}$ and related species of the genus Echinicola, the Average Nucleotide Identity (ANI) was calculated according to the online ANI Calculator (www.ezbiocloud.net/tools/ani)(Yoon et al. 2017). The Average Amino Acid identity (AAI) and digital DNA-DNA Hybridization (dDDH) were compared online by using (http://enve-omics.ce.gatech.edu/aai/) (Rodríguez-R and Konstantinidis 2014) and the Genome-to-Genome Distance Calculator (GGDC2.1)(http://ggdc.dsmz.de)(Meier-Kolthoff et al. 2013) respectively.

The DNA G + C content of strain P51 ${ }^{\mathrm{T}}$ was determined from the genome sequence. In this study, we have obtained and submitted the draft genome sequence of strain P51 ${ }^{\mathrm{T}}$, the GenBank/EMBL/DDBJ accession number for the whole genome sequence is JACODZ000000000. Genomic data of other type strains within the genus Echinicola were obtained from the GenBank/ENA/DDBJ databanks.

\section{Physiology and Chemotaxonomy}

Gram staining was performed as described earlier (Moyes et al. 2009). After incubating the bacterium on MA at $37{ }^{\circ} \mathrm{C}$ for 2 days, cell morphology and flagella were observed using an electron microscope (Jem-1200; JEOL). To investigate growth under anaerobic conditions, the strain was cultured on MA with or without $0.1 \%(\mathrm{w} / \mathrm{v}) \mathrm{NaNO}_{3}$ under anaerobic conditions at $37^{\circ} \mathrm{C}$ for 2 weeks.

Growth at $4,15,20,25,28,33,37,40,42,45$ and $50^{\circ} \mathrm{C}$ were determined using MA. 
The effect of $\mathrm{NaCl}$ on growth was tested in $\mathrm{NaCl}$-free artificial seawater medium supplemented with $5.0 \mathrm{~g}$ peptone, $1.0 \mathrm{~g}$ yeast extract, and various concentrations of $\mathrm{NaCl}$ (final concentration $0-15.0 \%$, in increments of $0.5 \%$ )(Yang and Cho 2008). The $\mathrm{pH}$ range for growth was determined in $\mathrm{MB}$ adjusted to $\mathrm{pH} 5.5-9.5$ with a concentration of $20 \mathrm{mM}$ using the following buffer systems: MES (pH 5.5 and 6.0), PIPES (pH 6.5 and 7.0), HEPES (pH 7.5 and 8.0), Tricine (pH 8.5), and CAPSO (pH 9.0 and 9.5). According to the Bowman's method (Bowman 2000), gliding motility was investigated using oil-immersion phase-contrast microscopy (AX70; Olympus). The activities of catalase and oxidase, hydrolysis of cellulose and agar, were tested according to the method described before (Tindall et al. 2007). Antibiotic sensitivity was assessed on MA plates with discs (Tianhe) containing various antibiotics for 3 days at $37^{\circ} \mathrm{C}$. According to the manufacturers' instructions, the oxidation and fermentation of carbohydrates were determined after growth on MA at $33{ }^{\circ} \mathrm{C}$ for 2 days using the Biolog GEN III Micro Plates and API 50CHB Fermentation Kit (bioMérieux). Other physiological tests were carried out using API 20E, API 20NE, and API ZYM strips (bioMérieux).

\section{Chemotaxonomic characterisation}

The bacteria of strain $\mathrm{P} 51^{\mathrm{T}}$ at the late stage of the exponential growth phase were collected and lyophilized to obtain freeze-dried cells. The five related type strains were both treated the same way. For fatty acid analysis, strain $\mathrm{P} 51^{\mathrm{T}}$ and related strains were incubated in $\mathrm{MB}$ at $33{ }^{\circ} \mathrm{C}$ until the mid-exponential phase. Under identical conditions, fatty acid methyl esters were extracted and analysed according to the 
standard MIDI (Microbial Identification) system (Sasser 1990) and identified by the TSBA6.0 database. For the analysis of respiratory quinone and polar lipids, the strain was harvested after incubation in $\mathrm{MB}$ at $33^{\circ} \mathrm{C}$ for 3 days. Respiratory quinones in strain $\mathrm{P} 51^{\mathrm{T}}$ were determined with HPLC (Hiraishi et al. 1996). Polar lipid analysis was performed by the Marine Culture Collection of China (MCCC), Xiamen, Fujian Province, P. R. China.

\section{Results and discussion}

\section{Phylogenetic analysis and whole genome sequencing}

The nearly complete $16 \mathrm{~S}$ rRNA gene sequence (1444 bp) was measured. 16S rRNA gene sequence comparisons showed that strain $\mathrm{P} 51^{\mathrm{T}}$ was most closely related to members of the genus Echinicola, with 16S rRNA gene sequence similarities of 97.7\% with 'E. shivajiensis' $\mathrm{AK} 12^{\mathrm{T}}$ and $97.0 \%$ with E. sediminis $001-\mathrm{Na} 2^{\mathrm{T}}$. The results of the phylogenetic analysis based on 16S rRNA gene sequences showed that strain $\mathrm{P} 51^{\mathrm{T}}$ fell within the cluster comprising the genus Echinicola (Fig. 1). Similar tree topologies were also obtained with the ML algorithms (Fig. S1).

The genome of strain $\mathrm{P} 51^{\mathrm{T}}$ was comprised of 4111 genes and 25 contigs with a total length of $5139782 \mathrm{bp}$. The N50 value was $513723 \mathrm{bp}$. There were $5 \mathrm{~S}$ rRNAs of $6,16 \mathrm{~S}$ rRNA of 2, 23S rRNAs of 2 and tRNAs of 43. According to the genome sequence, the DNA G + C content was 39.9 mol\%, which was outside the range of existing species of genus Echinicola (Kim et al. 2011; Liang et al. 2016)(43.8-46.9 mol\%). However, it was similar to that of unpublished species submitted in the NCBI, such as $39.8 \mathrm{~mol} \%$ at Echinicola sp. CAU 1574 (JACYTQ000000000) and 39.9 mol\% at Echinicola sp. 
20G (PRJDB10725). The KEGG pathway annotation annotated genes and most genes related to global and overview maps. A large number of genes were found to be involved in carbohydrate metabolism(194) and amino acid metabolism(171). Result of further genome sequences analysis showed that strain $\mathrm{P} 51^{\mathrm{T}}$ harboured pathway for carotenoid biosynthesis (Fig. S4), which may associated with the colour pigmented in the bacteria colony (Paniagua-Michel et al. 2012). Based on the genome sequence annotation, the genome contained several genes coding for Glycoside Hydrolases (GHs), Glycosyl Transferases (GTs) and Carbohydrate-Binding Modules (CBMs), such as fucosidase (14 GH29), mannosidase (13 GH2), cellulose synthase (25 GT2) and sucrose synthase (27 GT4), which indicated that the strain played an important role in the carbon cycle. The secondary metabolite of strain $\mathrm{P} 51^{\mathrm{T}}$ were predicted to terpene and bacteriocin, which were considered as important raw materials for drug synthesis. Genome mining analysis using antiSMASH-4.0.2 led to the identification of 2 putative gene clusters in the genome of strain $\mathrm{P} 51^{\mathrm{T}}$, including 23 genes that showed similarity to the known gene clusters of terpene and 10 genes that showed similarity to bacteriocin. Hence, it had great potential to biosynthesize secondary metabolite and produce novel bioactive compounds. One cluster showed $75 \%$ similarity to the reported biosynthetic gene cluster of terpene in Anditalea andensis ANESC-S ${ }^{\mathrm{T}}$ (Shi et al. 2012).

A complete 16S rRNA gene sequence (1444 bp) obtained from the genome sequence was $100.0 \%$ similar with the clone sequence (2665 bp and $1700 \mathrm{bp}$ ) deposited in GenBank under accession number MW110902.According to the data obtained, the ANI between strain $\mathrm{P} 51^{\mathrm{T}}$ and the other species tested were no more than $84.7 \%$, which were 
below the standard ANI criteria identity (95.0-96.0\%)(Kim et al. 2014). The dDDH comparison with the draft genome of strain $\mathrm{P} 51^{\mathrm{T}}$ yielded low percentages $(<28.2 \%)$ with all the species tested, which were far below the boundary $(70.0 \%)$ for new species identification (Meier-Kolthoff et al. 2013). The AAI values were between 70.8-74.0\% with the closely related type species. All the data were showed in Table. S1. Based on the genome sequence analysis, strain $\mathrm{P} 51^{\mathrm{T}}$ should be located within the genus Echinicola as a novel species.

\section{Morphology, physiology, and biochemical analysis}

Cells were Gram-stain-positive, aerobiotic, motile, gliding, lacking flagella, and rodshaped (0.3-0.4 $\mu \mathrm{m}$ in width, $1.5-2.8 \mu \mathrm{m}$ in length) (Fig. S2). A round pink colony with a diameter of $1.5 \mathrm{~mm}$ was obtained after incubating on MA for $2-3$ days at $33{ }^{\circ} \mathrm{C}$. Catalase-positive and oxidase-negative. Growth was observed at $4-42{ }^{\circ} \mathrm{C}$ (optimum $33{ }^{\circ} \mathrm{C}$ ), $\mathrm{pH} 4.0-9.0$ (optimum 7.0). It could grow at $4{ }^{\circ} \mathrm{C}$, which was different from related strains. The $\mathrm{NaCl}$ concentrations for growth were $0-11.0 \%$ (optimum $4.0 \%$ ). Susceptible to penicillin, cefazolin, erythromycin, norfloxacin, ciprofloxacin, trimethoprim-sulfamethoxazole, chloramphenicol. Resistant to ampicillin, amikacin, gentamicin. The resistance to ampicillin was consistent with genome analysis about $\beta$ lactam resistance in KEGG pathway annotation (Fernández and Hancock 2012) (Fig. S5). Other phenotypic characteristics of the strain $\mathrm{P} 51^{\mathrm{T}}$ and related strains are shown in Table 1.

\section{Chemotaxonomic characterization}

The main fatty acids $(>5.0 \%)$ of strain $\mathrm{P} 51^{\mathrm{T}}$ were iso- $\mathrm{C}_{15: 0}(34.5 \%)$, summed feature 3 
I) $(5.9 \%)$ and summed feature 9 (iso- $\mathrm{C}_{17: 1} \omega 9 c$ and/or 10-methyl $\left.\mathrm{C}_{16: 0}\right)(8.5 \%)$. Fatty acid profiles of the strain $\mathrm{P} 51^{\mathrm{T}}$ and related strains were shown in Table 2. The sole menaquinone of strain $\mathrm{P} 51^{\mathrm{T}}$ was MK-7, which was consistent with other members of the genus Echinicola (Kim et al. 2011; Lee et al. 2017; Nedashkovskaya et al. 2007;

Nedashkovskaya et al. 2006; Srinivas et al. 2012). The polar lipids included one phosphatidylethanolamine, one unidentified aminophospholipid, one unidentified phospholipid, three unidentified aminolipids and one unknown lipid (Fig. S3). Species in the genus Echinicola also had the same polar lipids as phosphatidylethanolamine and one unidentified aminophospholipid. Besides they were different in the number of unidentified lipids from 'E. shivajiensis' $\mathrm{AK} 12^{\mathrm{T}}$ (six)(Srinivas et al. 2012) and $E$. sediminis $001-\mathrm{Na}^{\mathrm{T}}{ }^{\mathrm{T}}$ (three)(Lee et al. 2017), which was the distinction between strain $\mathrm{P} 51^{\mathrm{T}}$ and the related strains.

In conclusion, the phenotypic properties and phylogenetic analyses suggest that the strain $\mathrm{P} 51^{\mathrm{T}}$ can be differentiated from other species of the genus Echinicola, for which the name Echinicola salinicaeni is proposed.

\section{DESCRIPTION OF ECHINICOLASALINICAENI SP. NOV.}

Echinicola salinicaeni (sa.li.ni.cae'ni. N.L. masc. adj. salinus saline; L. neut. n. caenu $m$ mud, silt; N.L. gen. n. salinicaeni of saline silt).

Cells are Gram-stain-positive, aerobiotic, motile, gliding, and rod-shaped. Colonies on MA are convex, circular, smooth and pink with entire margins. Cells are $0.3-0.4 \mu \mathrm{m}$ in width and $1.5-2.8 \mu \mathrm{m}$ in length after incubating on MA at $37^{\circ} \mathrm{C}$ for 2 days. Growth 
$\mathrm{NaCl}$ (optimum 4.0\%). Catalase and oxidase are positive. Cells cannot hydrolyse

alginate, cellulose and agar. Positive for alkaline phosphatase, leucine arylamidase,

valine arylamidase, cystine arylamidase, trypsin, $\alpha$-chymotrypsin, acid phosphatase,

and $\mathrm{N}$-acetyl- $\beta$-glucosaminidase, $\alpha$-mannosidase and $\alpha$-fucosidase are present, but

esterase (C4), esterase lipase (C8), lipase (C14) and $\beta$-glucuronidase are

absent. Carbon source oxidation tests are negative for 3-methyl-D-glucoside, D-

fucose, inosine, fusidic acid, D-sorbitol, D-mannitol, D-arabitol, D-aspartic-acid, D-

serine, troleandomycin, minocycline, L-arginine, L-histidine, L-pyroglutamic acid,

lincomycin, niaproof 4, D-gluconic acid, mucic acid, quinic acid, D-saccharic acid,

tetrazolium violet, $p$-hydroxyphenylacetic acid, D-lactic acid methyl ester, citric acid,

$\alpha$-ketoglutaric acid, D-malic acid, bromosuccinic acid, nalidixic acid, potassium

tellurite, $\gamma$-amino-butryric acid, $\alpha$-hydroxy-butyric acid, $\beta$-hydroxy-D,L-butyric acid,

$\alpha$-keto-butyric acid, acetoacetic acid, acetic acid, sodium butyrate and sodium

bromate while positive for all other tested carbon sources. Acid is produced from L-

arabinose, D-xylose, D-galactose, D-glucose, D-fructose, D-mannose, methyl- $\alpha$-D-

mannopyranoside, methyl- $\alpha$-D-glucopyranoside, N-acetylglucosamine, arbutin,

esculin, D-cellobiose, D-maltose, D-lactose, sucrose, trehalose, inulin, raffinose,

turanose and L-fucose, but not from glycerol, erythritol, L-xylose, D-adonitol, dulcitol, 
the API 20NE tests, strain $\mathrm{P} 51^{\mathrm{T}}$ is positive for D-glucose fermentation, hydrolysis of esculin and 4-nitrophenyl- $\beta$-D-galactopyranoside, but negative for nitrate reduction which corresponding to the genomic analysis, indole production, arginine dihydrolase, hydrolysis of gelatin and urea. Additionally, strain $\mathrm{P} 51^{\mathrm{T}}$ is negative for assimilation of L-arabinose, D-mannose, D-mannitol, N-acetylglucosamine, D-maltose, potassium gluconate, capric acid, adipic acid, malic acid, trisodium citrate and phenylacetic acid. The cells are positive for $\beta$-galactosidase and glucose acidification, but negative for gelatin, arginine dehydratase, lysine decarboxylase, ornithine decarboxylase, citrate utilization, $\mathrm{H}_{2} \mathrm{~S}$ production, urease, indole production, tryptophan deaminase.

The type strain, $\mathrm{P} 51^{\mathrm{T}}=\left(\mathrm{KCTC} 82513^{\mathrm{T}}=\mathrm{MCCC} 1 \mathrm{~K} 04413^{\mathrm{T}}\right)$ was isolated from silt samples in Muping saltern in Yantai, Shandong Province, People's Republic of China. The GenBank/EMBL/DDBJ accession number for the 16S rRNA gene sequence of strain $\mathrm{P}^{2} 1^{\mathrm{T}}$ is $\mathrm{MW} 110902$ and the number for the whole genome sequence is JACODZ000000000.

\section{References}

Aziz RK et al. (2008) The RAST Server: rapid annotations using subsystems technology BMC Genomics 9:75 doi:10.1186/1471-2164-9-75

Blin K et al. (2019) antiSMASH 5.0: updates to the secondary metabolite genome mining pipeline Nucleic Acids Res 47:W81-W87 doi:10.1093/nar/gkz310

Bowman JP (2000) Description of Cellulophaga algicola sp. nov., isolated from the surfaces of Antarctic algae, and reclassification of Cytophaga uliginosa (ZoBell and Upham 1944) Reichenbach 1989 as Cellulophaga uliginosa comb. nov Int 
Consortium TU (2019) UniProt: a worldwide hub of protein knowledge Nucleic Acids Res 47:D506-D515 doi:10.1093/nar/gky1049

Fernández L, Hancock REW (2012) Adaptive and Mutational Resistance: Role of Porins and Efflux Pumps in Drug Resistance Clinical Microbiology Reviews 25:661-681 doi:doi:10.1128/CMR.00043-12

Hiraishi A, Ueda Y, Ishihara J, Mori T (1996) Comparative lipoquinone analysis of influent sewage and activated sludge by high-performance liquid chromatography and photodiode array detection The Journal of General and Applied Microbiology 42:457-469 doi:10.2323/jgam.42.457

Jung YJ, Yang SH, Kwon KK, Bae SS (2017) Echinicola strongylocentroti sp. nov., isolated from a sea urchin Strongylocentrotus intermedius International Journal of Systematic and Evolutionary Microbiology 67:670-675 doi:10.1099/ijsem.0.001691

Kanehisa M, Sato Y, Kawashima M, Furumichi M, Tanabe M (2016) KEGG as a reference resource for gene and protein annotation Nucleic Acids Res 44:D457462 doi:10.1093/nar/gkv1070

Kim H, Joung Y, Ahn TS, Joh K (2011) Echinicola jeungdonensis sp. nov., isolated from a solar saltern International Journal of Systematic and Evolutionary Microbiology 61:2065-2068 doi:10.1128/9781555817497

Kim M, Oh H-S, Park S-C, Chun J (2014) Towards a taxonomic coherence between average nucleotide identity and 16S rRNA gene sequence similarity for species 
demarcation of prokaryotes International journal of systematic and evolutionary microbiology 64:346-351 doi:10.1099/ijs.0.059774-0

Kumar S, Stecher G, Tamura K (2016) MEGA7: Molecular Evolutionary Genetics Analysis Version 7.0 for Bigger Datasets Molecular Biology and Evolution 33:1870-1874 doi:10.1093/molbev/msw054

Lee DW, Lee AH, Lee H, Kim JJ, Khim JS, Yim UH, Kim BS (2017) Echinicola sediminis sp. nov., a marine bacterium isolated from coastal sediment International Journal of Systematic and Evolutionary Microbiology 67:33513357 doi:10.1099/ijsem.0.002118

Liang P, Sun J, Li H, Liu M, Xue Z, Zhang Y (2016) Echinicola rosea sp. nov., a marine bacterium isolated from surface seawater International Journal of Systematic and Evolutionary Microbiology 66:3299-3304 doi:10.1099/ijsem.0.001191

Meier-Kolthoff JP, Auch AF, Klenk HP, Goker M (2013) Genome sequence-based species delimitation with confidence intervals and improved distance functions BMC Bioinformatics 14:60 doi:10.1186/1471-2105-14-60

Moyes RB, Reynolds J, Breakwell DP (2009) Differential staining of bacteria: gram stain Curr Protoc Microbiol Appendix 3:Appendix 3C doi:10.1002/9780471729259.mca03cs15

Nedashkovskaya OI, Kim SB, Hoste B, Shin DS, Beleneva IA, Vancanneyt M, Mikhailov VV (2007) Echinicola vietnamensis sp. nov., a member of the phylum Bacteroidetes isolated from seawater International Journal of $\begin{array}{llll}\text { Systematic and } \quad \text { Evolutionary } & \text { Microbiology }\end{array}$ 
319 Nedashkovskaya OI et al. (2006) Echinicola pacifica gen. nov., sp. nov., a novel flexibacterium isolated from the sea urchin Strongylocentrotus intermedius International Journal of Systematic and Evolutionary Microbiology 56:953-958 doi:10.1099/ijs.0.64156-0

Paniagua-Michel J, Olmos-Soto J, Ruiz MA (2012) Pathways of carotenoid biosynthesis in bacteria and microalgae Methods Mol Biol 892:1-12 doi:10.1007/978-1-61779-879-5_1

Rodríguez-R L, Konstantinidis KT (2014) Bypassing Cultivation to identify bacterial species Microbe 9:111-118

Sasser M (1990) Identification of bacteria by gas chromatography of cellular fatty acids USFCC Newsl 20:1-6

Shi W, Takano T, Liu S (2012) Anditalea andensis gen. nov., sp. nov., an alkaliphilic, halotolerant bacterium isolated from extreme alkali-saline soil Antonie van Leeuwenhoek 102:703-710 doi:10.1007/s10482-012-9770-7

Srinivas TN, Kailash Tryambak B, Anil Kumar P (2012) Echinicola shivajiensis sp. nov., a novel bacterium of the family "Cyclobacteriaceae" isolated from brackish water pond Antonie Van Leeuwenhoek 101:641-647 doi:10.1007/s10482-011-9679-6

Tindall BJ, Sikorski J, Smibert RA, Krieg NR (2007) Phenotypic Characterization and the Principles of Comparative Systematics. In: Methods for General and Molecular

Microbiology.

$\mathrm{pp}$ 330-393. 
341 Vandamme P, Pot B, Gillis M, de Vos P, Kersters K, Swings J (1996) Polyphasic Technology Program of Weihai (1070413421511).

\section{Acknowledgements}


We thank Prof. Aharon Oren for his valuable help with naming the species.

\section{Conflicts of interest}

364 Authors declare that there is no conflict of interest.

\section{Ethical approval}

366 This article does not contain any studies with human participants or animals performed 367 by any of the authors.

\section{Data availability statement}

369 All data generated or analysed during this study are included in this published article,

370 its supplementary information files and GenBank/EMBL/DDBJ. The

371 GenBank/EMBL/DDBJ accession number for the 16S rRNA gene sequence of strain

$372 \mathrm{P}^{\mathrm{T}} 1^{\mathrm{T}}$ is MW110902 and the number for the whole genome sequence is

373 JACODZ000000000. Supplementary figures and Supplementary tables are available

374 with the online version of this paper.

\section{Authors' contributions}

376 HZ drafted the manuscript. CYS, HZ, YJY, and YXZ performed isolation, deposition

377 and identification. RY, HZ and STY performed genome analysis. YXL revised the manuscript. YXZ designed all the experiments and supervised the manuscript. 


\section{Figures}

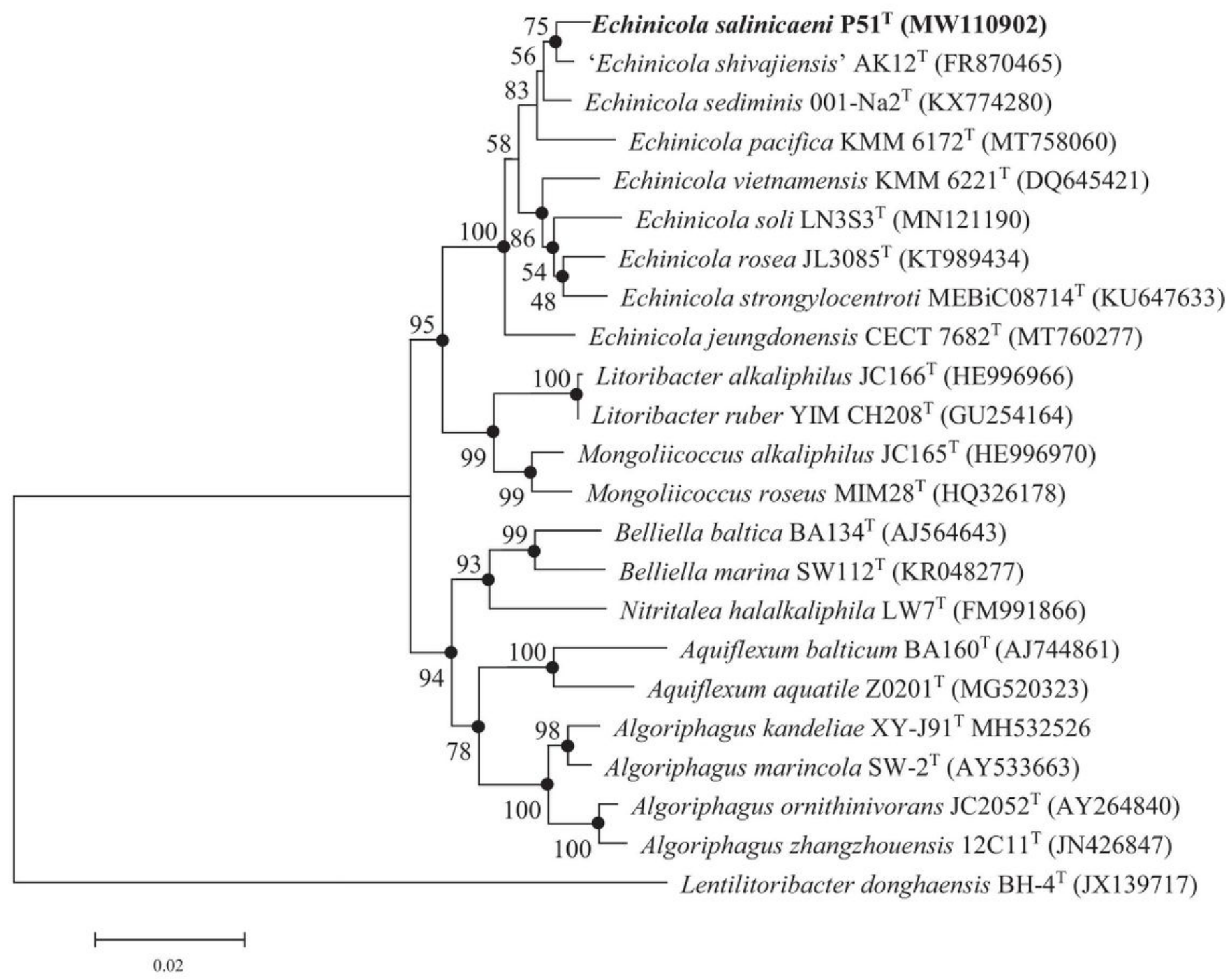

\section{Figure 1}

Neighbour-joining phylogenetic tree based on 16S rRNA gene sequences of strain P51T and high similarity of genus. Bootstrap values $(>50 \%)$ based on 1000 resamplings are shown at branch nodes. Filled circles indicate that the corresponding nodes were recovered in trees generated by the neighbourjoining, maximum-likelihood methods. Lentilitoribacter donghaensis BH-4T was used as an outgroup. Bar, 0.02 substitutions per nucleotide position.

\section{Supplementary Files}

This is a list of supplementary files associated with this preprint. Click to download. 
- 4P51SupplementaryMaterials.pdf 